\title{
A 3 min reasoning test based on grammatical transformation
}

\author{
A. D. BADDELEY 1 \\ MEDICAL RESEARCH COUNCIL, APPLIED PSYCHOLOGY RESEARCH UNIT, CAMBRIDGE, ENGLAND
}

A simple reasoning test involving the understanding of sentences of various levels of syntactic complexity is described. It is short, easily administered, and reliable. Performance correlates with intelligence $(+.59)$ and has proved to be sensitive to a number of stresses.

In investigating the effects on human performance of environmental stresses or drugs, it is often desirable to sample a wide range of tasks in a very limited amount of time. There is therefore need for a battery of performance tests which are short and easy to administer, and which at the same time are valid, reliable, and sensitive. While short tests of motor skill (Legge, Steinberg, \& Summerfield, 1957) and simple addition (Baddeley \& Flemming, 1967) are already available, there does not appear to be a suitable test involving "higher mental processes." The present report describes an attempt to fill this gap.

Recent studies in psycholinguistics have shown that the time taken to understand a sentence is closely dependent on its syntactic structure, with positive statements being understood more quickly than negatives, active statements more rapidly than passives, and true statements faster than false (Wason, 1961; Slobin, 1966). Transformations should provide an intellectual task which is familiar enough to all Ss to be performed very rapidly, and yet be sufficiently demanding to be sensitive to any fall in intellectual capacity. It is also easily adapted for group testing. Procedure

Subjects first read the following instructions and attempted the examples: "In the following test there are a number of short sentences each followed by a pair of letters ( $A B$ or $B A)$. The sentences claim to describe the order of the two letters, i.e., to say which comes first. They can do this in several different ways. Thus the order AB can be correctly described by saying either (1) A precedes $B$, or (2) B follows A, or (3) B does not precede A, or (4) A does not follow B. All these are correct descriptions of the pair $A B$ but are incorrect when applied to the other pair, BA.

'Your job is to read each sentence and to decide whether it is a true or false description of the letter pair which follows it. If you think that the sentence describes the letter pair correctly put a tick in the first column (labeled "True"). If you think the sentence does not give a true description of the letter order, put a tick in the second ("False") column.
"This is illustrated in examples 1 and 2 below. When you have read 1 and 2 , try examples $3,4,5$, and 6.
1. A follows $B-B A$
2. $B$ precedes $A-A B$
3. $A$ is followed by $B-A B$
4. $B$ is not followed by $A-B A$
5. $B$ is preceded by $A-B A$
6. A does not precede $B-B A$

"When you start the main test, work as quickly as you can without making mistakes. Start with sentence 1 and work systematically through the test leaving no blank spaces."

The test comprised all 64 possible combinations of the following six binary conditions: (1) Positive or Negative, (2) Active or Passive, (3) True or False, (4) Precedes or Follows, (5) A or B mentioned first, (6) Letter pair $A B$ or BA. Five different test forms were produced with the 63 items occurring in a different random order on each. The Ss were allowed $3 \mathrm{~min}$ to complete as many items as possible.

Results

Total items correct has generally proved the most sensitive score and is used in the analysis which follows.

The task proved easy to administer and has been used successfully for populations ranging from army recruits to graduate students.

Validity. Apart from its considerable face-validity, the assumption that this is a task involving "higher mental processes" is supported by its correlation with intelligence test scores. A study involving 29 enlisted men showed a correlation of +.59 with performance on the British Army verbal intelligence test $(\mathrm{p}<.001)$.

Reliability. A study in which Ss $(\mathrm{N}=18)$ were tested twice on successive days showed a mean correlation of +.80 between performance on the two days (Baddeley et al, in press).

Practice effects. The extent of the practice effect is reasonably small after the initial trial; e.g., enlisted men performing the task five times in $1 \mathrm{~h}$ scored a mean of $32.9,37.5,39.1,39.6$, and 41.9 correct items on runs 1-5, respectively.

Sensitivity. The task has so far been used in three stress studies. It was first used to study nitrogen narcosis, the intoxication which occurs when air is breathed at high pressure (Baddeley et al, in press). 
Divers performed a waterproof version of the test at depths of 5 and $100 \mathrm{ft}$ (the shallowest depth at which narcosis is generally accepted to be present). On successive days impairments in speed occurred of $17.0 \%(\mathrm{~T}=26, \mathrm{~N}=17, \mathrm{p}<.02)$ and $12.7 \%(\mathrm{~T}=6.5$, $\mathrm{N}=17, \mathrm{p}<.01$ ).

In a second study (Brown, Tickner, \& Simmonds, in preparation) an auditory version of the test was used as a supplementary task in a car driving study. When Ss attempted to perform the task while driving, there was a drop of $44 \%$ in speed and $28 \%$ in accuracy coupled with a $32 \%$ decrease in the driver's ability to judge whether a gap was wide enough to drive the car through, although his skill in handling the car was unimpaired.

In a third study (Baddeley, in preparation), 22 Ss performed the task in loud white noise $(103 \mathrm{~dB})$ and in quiet $(60 \mathrm{~dB})$. While noise had no overall effect, it interacted with temperament, with extroverts tending to improve and introverts tending to deteriorate, giving a correlation of $+.56 \quad(p<.01)$ between degree of decrement and introversion as measured by the Heron (1956) unsociability scale.

In conclusion, the grammatical transformation test seems to offer a short, easily administered reasoning test of acceptable validity, reliability, and sensitivity.

References

BADDELEY, A. D., DE FIGUEREDO, J. W., HAWKSWELL CURTIS, J. W., \& WILLIAMS. A. N. Nitrogen narcosis and performance under water. Ergonomics, in press.

BADDELEY, A. D., \& FLEMMING, N. C. The efficiency of divers breathing oxy-heilum. Ergonomics. 1967, 10,311-319.

HERON, A. A two-part personality measure for use as a research criterion. Brit. J. Psychol., 1956, 47, 243-251.

LEGGE, D., STEINBERG, H., \& SUMMERFIELD, A. Simple measures of handwriting as indices of drug effects. Percept. mot. Skills, 1957, $18,549-558$.

SLOBIN, D. I. Grammatical transformations and sentence comprehension in childhood and adulthood. J. verb. Learn. verb. Behav., 1966, 5, 219-227.

WASON, P. C. Response to affirmative and negative binary statements. Brit. J. Psychol, 1961, 52, 133-142.

Note.

1. Now at Experimental Psychology Laboratory, University of Sussex. 